Data repository file for article G33486 - Lake sediments record cycles of sediment flux driven by large earthquakes on the Alpine Fault, New Zealand.

\title{
Explanatory notes on methods.
}

\section{Sedimentological methods}

Three $6 \mathrm{~m}$ (50 $\mathrm{mm}$ internal diameter) sediment cores were extracted from the Windbag Basin of Lake Paringa using a Mackereth corer. Cores were logged visually and their physical properties characterised using a GEOTEK multi sensor core logger. Sedimentary deposits were characterised using grain-size, total organic carbon (TOC), $\mathrm{C} / \mathrm{N}$ ratios and unsupported ${ }^{210} \mathrm{~Pb}$. Grain-size samples were taken at $2.5 \mathrm{~mm}$ resolution through five subsets of each sedimentary deposit in cores PA1, PA4 and PA5. These samples were pre-treated to remove organic material and biogenic silica. Pre-treated samples were analysed on a Malvern Mastersizer $2000^{\mathrm{TM}}$ using the procedure and optical properties for natural sediments recommended by Sperazza et al. (2004). Grain-size fractions and means were calculated using the method of Folk and Ward (1957).

Total organic carbon and $\mathrm{C} / \mathrm{N}$ ratios were determined at $10 \mathrm{~mm}$ intervals down core PA1 on $300 \mathrm{mg}$ sub-samples by combusting at $900 \mathrm{C}$ in a Verio $\mathrm{Max}^{\mathrm{TM}}$ elemental analyser operating using a gluatmic acid standard. Before analysis all samples were tested for the presence/absence of carbonates by submerging a sub-sample in 6N HCL and observing for an effervescent reaction. None of the samples exhibited such a reaction and so total carbon was regarded as equivalent to TOC. In the absence of carbonate the decision not to pre-treat the samples with acid was regarded as a conservative approach given recent studies that demonstrate substantial non-linear variation in organic $\mathrm{C}$ and $\mathrm{N}$ concentrations caused by acid pre-treatment (Brodie et al., 2011; Fernandes and Kull, 2008). Procedural blanks demonstrated that contamination from $\mathrm{C}$ and $\mathrm{N}$ during the preparation procedure was minimal but present. Therefore, all sample $\mathrm{C}$ and $\mathrm{N}$ values were corrected for an average procedural blank $(n=20)$ of $\mathrm{N}=0.00139 \%(\sigma 0.00110)$ and $\mathrm{C}=0.00878 \%(\sigma 0.00441)$.

The concentration of ${ }^{210} \mathrm{~Pb}$ was determined on 24 samples from the top of core PA1 (Fig. DR2). Unsupported ${ }^{210} \mathrm{~Pb}\left({ }^{210} \mathrm{~Pb}\right.$ ex $)$ was determined by measuring ${ }^{210} \mathrm{Po}$ activity using alpha spectrometry to provide a measure of total ${ }^{210} \mathrm{~Pb}$ activity in the sediment and then subtracting the portion of supported ${ }^{210} \mathrm{~Pb}$ produced by in-situ decay of ${ }^{226} \mathrm{Ra}$. Average concentrations of supported ${ }^{210} \mathrm{~Pb}$ were determined by measuring ${ }^{226} \mathrm{Ra}$ concentrations by gamma spectrometry on a representative subset of samples. Alpha and beta counting was conducted at the National Isotope Centre, GNS Science.

The dry mass $\left(\mathrm{M}_{\text {dry }}\right)$ of clastic sediment was used as a proxy for sediment flux from the lake catchment and was calculated at $10 \mathrm{~mm}$ increments down core PA1 using equation 1:

$$
M_{d r y}=\left(\frac{M_{w e t}}{\left(1+\frac{W}{100}\right)}\right)-\left(\left(\frac{M_{w e t}}{\left(1+\frac{W}{100}\right)}\right) \times\left(\frac{F(T O C)}{100}\right)\right)
$$


Where $\mathrm{M}_{\text {wet }}$ is wet mass $(\mathrm{g}), \mathrm{W}$ is weight percentage water content (\%), TOC is total organic carbon (\%) and $\mathrm{F}$ is the Van Bemmelen factor of 1.724 for converting weight percent TOC to weight percent organic matter (Rowel, 1994). Microscopy indicates that biogenic silica represents a very small fraction of the total mass at any given depth and was considered insignificant for the computation of the dry density of clastic sediment.

\section{Methods for establishing chronology}

Chronology was established by radiocarbon dating 22 terrestrial leaf macrofossils extracted from undisturbed sedimentary horizons in core PA1 (Table DR1). Leaf macrofossils were pre-treated, combusted and graphitized according to standard methods (Hua et al., 2001). Samples were analysed using Accelerator Mass Spectrometry at the ANTARES AMS Centre at ANSTO (Australian Nuclear Science and Technology Organization) according to the methods of Fink et al. (2004).

To produce ages comparable to calendar years, radiocarbon dates must be calibrated to account for variation in the concentration of atmospheric radiocarbon in the past. This is problematic during the last 2000 years because high amplitude variation in the concentration of atmospheric radiocarbon means that individual radiocarbon ages have large errors when calibrated into calendar ages (Hua, 2009). However, precise calendar age calibration was established by combining the 22 radiocarbon dates with stratigraphic information in a Markov chain Monte Carlo (MCMC) model using the program OxCal 4.1 (Bronk Ramsey, 2008).

The OxCal model was run by normalising the depth record of core PA1 to remove depth associated with rapidly deposited layers such as megaturbidites and hyperpycnal turbidites that had thicknesses greater than $5 \mathrm{~mm}$. Layers of these deposits were removed because they do not represent the significant passage of time as the processes that deposited them occur on timescales of days to weeks rather than years, which is the minimum resolution of the radiocarbon chronology. The depth information and radiocarbon dates were combined with the Southern Hemisphere calibration curve (McCormac et al., 2004) using the $P_{-}$sequence algorithm.

The $\mathrm{P}$ _sequence algorithm treats deposition as a Poisson process where the time between depositional events is defined by the Poisson distribution and the size of individual events by the constant $k$. These depositional conditions are regarded as an acceptable approximation of lacustrine depositional settings (Blockley et al., 2008; Bronk Ramsey, 2008). An optimum value for $k=2$ was defined using the methodology outlined in Blockley et al. (2008) and boundaries prescribed directly above and below the first and last radiocarbon date in the record. The fit between the model output and the original data was $63 \%$, which is within the acceptable bound of fit (Bronk Ramsey, 2008). The age model produced by the above procedure was used to derive the timing of megaturbidite deposition, the end of post seismic landscape responses and the duration of post-seismic and asesimic sedimentary phases (Fig. DR3). 
Post-seismic and aseismic sedimentation rates were calculated by dividing the mass of clastic sediment $\left(\mathrm{M}_{\mathrm{CS}}\right)$ of each depositional phase by duration. The duration of each sedimentary phase was determined by querying the $\mathrm{P}_{-}$sequence chronologies for core PA1 using the function 'Difference' in OxCal 4.1, which produced a mean and standard deviation of these durations. The mean and standard deviation define the normally distributed PDFs for these durations and consequently, the $2 \sigma$ error represents the 95.6\% HPDF best estimate of these parameters. The average postseismic sediment pulse duration and average post-seismic and aseismic sedimentation rates were calculated using the arithmetic mean of these parameters (Taylor, 1997).

The impact of Alpine Fault earthquakes on sediment flux was quantified by calculating the proportion of the total mass of clastic sediment (TCS) deposited in post-seismic deposits. Total mass of clastic sediment was defined as the mass of clastic sediment in the five complete seismic cycles recorded in core PA1, excluding megaturbidite deposits. Sediment from megaturbidites was excluded because they contain material reworked from other lacustrine deposits and do not represent sediment flux from the fluvial catchment. The $\mathrm{M}_{\mathrm{CS}}$ in post-seismic deposits is not just composed of sediment produced by the landscape response to earthquakes because a portion of sediment flux over the response duration would have occurred regardless of the earthquake induced disturbance at a rate defined by the average aseismic sedimentation rate (cf. Hovius et al., 2011). The mass of this expected sediment $\left(\mathrm{PM}_{\mathrm{exp}}\right)$ was calculated using equation 2:

$$
P M_{\exp }=T_{p}\left(R_{a}\right)
$$

Where $T_{p}$ is the combined duration of all post-seismic sedimentary phases and $\mathrm{R}_{\mathrm{a}}$ is the average aseismic sedimentation rate. The percentage of TCS deposited as excess clastic sediment in post-seismic deposits $\left(\mathrm{M}_{\mathrm{eq}}\right)$, which is directly attributable to earthquakes, was determined using equation 3 :

$$
M_{e q}=\left(\frac{P M_{\text {total }}-P M_{\text {exp }}}{T C S}\right) * 100
$$

All errors are reported as 95\% HPDF for the parameters and have been derived by propagating the error from the chronology through the calculations using standard methods outlined in Taylor (1997) (Table DR2).

References:

Blockley, S.P.E., Ramsey, C.B., Lane, C.S. \& Lotter, A.F., 2008, Improved age modelling approaches as exemplified by the revised chronology for the Central European varved Lake Soppensee: Quaternary Science Reviews, v. 27, 61-71.

Brodie, C. R., Leng, M. J., Casford, J. S. L., Kendrick, C. P., Lloyd, J. M., Yongqiang, Z. \& Bird, M. I. 2011, Evidence for bias in $\mathrm{C}$ and $\mathrm{N}$ concentrations and $\delta^{13} \mathrm{C}$ composition of terrestrial and aquatic organic materials due to pre-analysis acid preparation methods. Chemical Geology, v. 282, p. 67-83.

Bronk Ramsey, C., 2008, Deposition models for chronological records: Quaternary Science Reviews, v. 27, p. $42-60$.

Fernandes, M. \& Krull, E. 2008, How does acid treatment to remove carbonates affect the isotopic and elemental composition of soils and sediments? Environmental Chemistry, v. 5, p. 33-39. 
Folk, R.L. and Ward, W.C., 1957, Brazos Rive bar: a study in the significance of grain sine parameters: Journal of Sedimentary Petrology, v. 27, 3-32.

Fink, D., Hotchkis, M., Hua, Q., Jacobsen, G., Smith, A. M., Zoppi, U., Child, D., Mifsud, C., van der Gaast, H., Williams, A. and Williams, M., 2004, The ANTARES AMS facility at ANSTO: NIM B, v. 223-224, 109-115.

Hua, Q., Jacobsen, G.E., Zoppi, U., Lawson, E. M., Williams, A.A., Smith, A.M. and McGann, M.J., 2001, Progress in radiocarbon target preparation at the ANTARES AMS Centre: Radiocarbon, v. 43, 275-282.

Hua, Q., 2009, Radiocarbon: A chronological tool for the recent past: Quaternary Geochronology, v.4, 378-390.

Hovius, N., Meunier, P., Lin, C.W., Chen, H., Chen, Y.G., Dadson, S., Horng, M.J. and Lines, M., 2011, Prolonged seismically induced erosion and the mass balance of a large earthquake: Earth and Planetary Science Letters, v. 304, p. 347-355.

McCormac, F.G., Hogg, A.G., Blackwell, P.G., Buck, C.E., Higham, T.F.G., and Reimer, P. J. 2004, SHCal04 Southern Hemisphere calibration, 0-11.0 cal kyr BP: Radiocarbon, v. 46, p. $1087-$ 1092.

Rowell, D.A. 1994, Soil Science: methods and applications: New York, Wiley.

Sperazza, M., Moore, J.N. \& Hendrix, M.S., 2004, High-resolution particle size analysis of naturally occurring very fine-grained sediment through laser diffractometry: Journal of Sedimentary Research, v. 74, 736-743.

Taylor, J.R. An introduction to error analysis: the study of uncertainties in physical measurements: California, University Science Books, 327 p. 


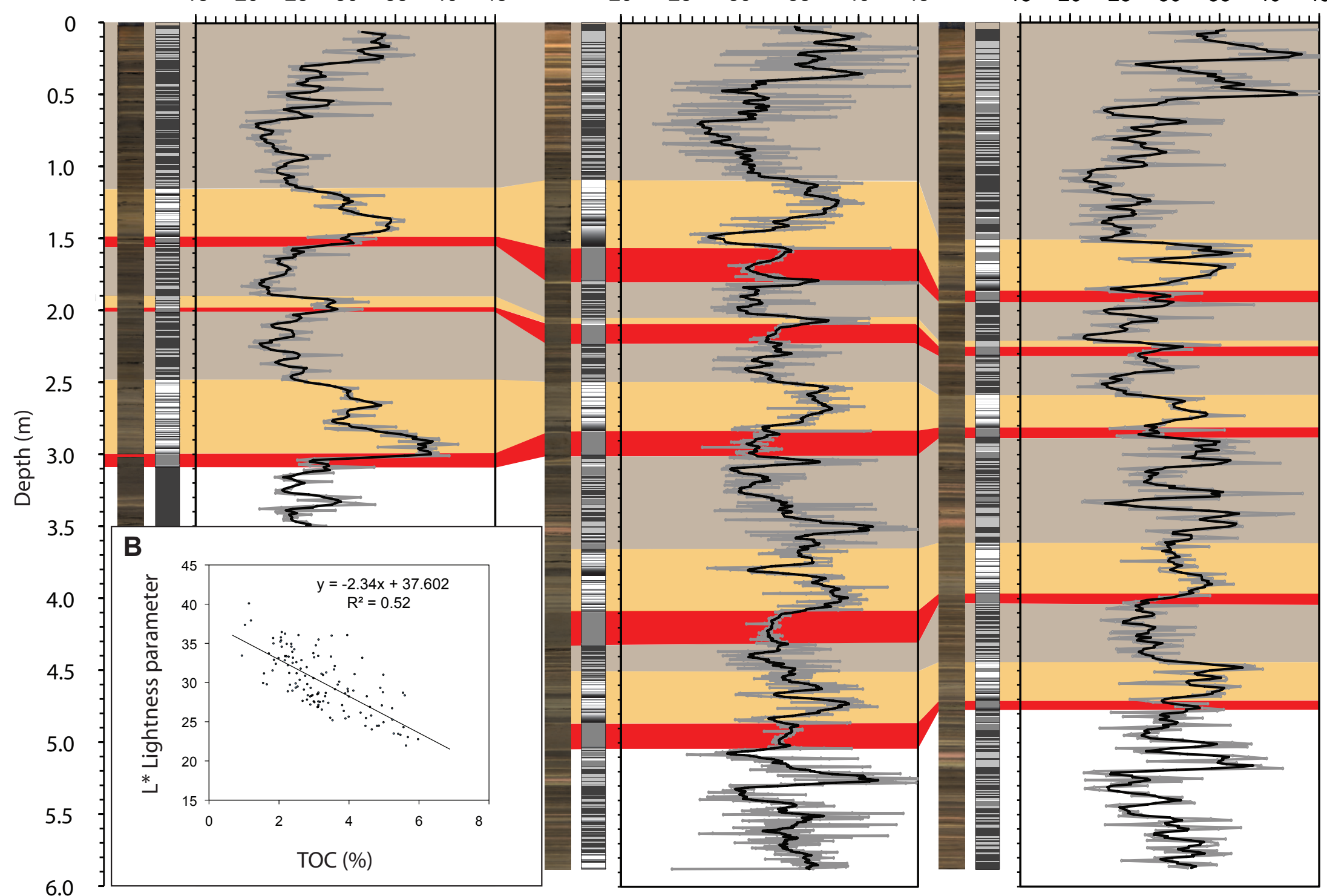

Figure DR1: a) Digital images, graphic logs and L* lightness parameter at $1 \mathrm{~cm}$ (grey) and $5 \mathrm{~cm}$ running average (black) resolution derived from the MSCL spectrophotometer data for the three $6 \mathrm{~m}$ Lake Paringa cores. The logs and $\mathrm{L}^{*}$ data demonstrate that the phases of aseismic and post-seismic sedimentation are of a relatively consistent thickness across the basin. The lower $3 \mathrm{~m}$ of core PA4 is composed of disturbed lamina, indicative of deformed basin plain sediments proximal to sub-aqueous slumping deposits. b) $L^{*}$ can be regarded as a proxy for TOC because the relationship between these parameters can be explained by a negative linear relationship with a $R^{2}$ value of 0.52 . 


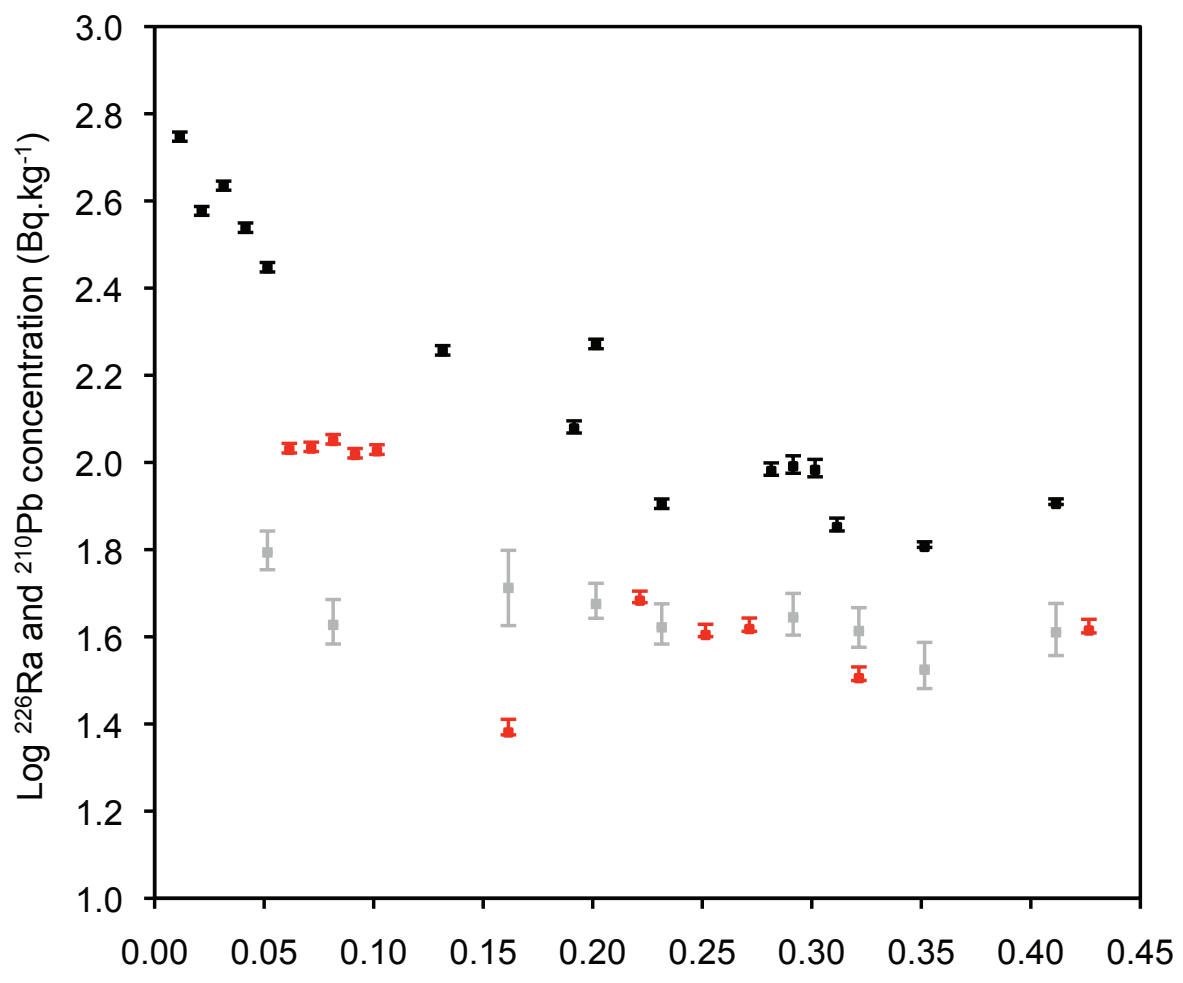

Core depth $(\mathrm{m})$

$\square$ Very fine sandy silt ${ }^{210} \mathrm{~Pb}$ concentration

Medium silt ${ }^{210} \mathrm{~Pb}$ concentration

Supported ${ }^{210} \mathrm{~Pb}$ concentration of sediment

Figure DR2: Log ${ }^{210} \mathrm{~Pb}$ concentrations for very fine sandy silts (black) and medium silts (red) and supported ${ }^{210} \mathrm{~Pb}$ of sediment (gray) from the top of core PA1. ${ }^{210} \mathrm{~Pb}$ concentrations of medium silt are not appreciably different to the concentration of ${ }^{210} \mathrm{~Pb}$ supported by the sediment showing that these sediment contain very low levels of unsupported ${ }^{210} \mathrm{~Pb}\left({ }^{210} \mathrm{~Pb}\right.$ ex $)$. The very low levels of ${ }^{210} \mathrm{~Pb}$ ex in medium silts are interpreted as the product of rapid accumulation of these fluvially derived sediments because ${ }^{210} \mathrm{~Pb}$ ex is produced in the atmosphere and is incorporated into lake sediment primarily by atmospheric fallout and so only accumulates to high concentrations in sediments deposited gradually. The ${ }^{210} \mathrm{~Pb}_{\mathrm{ex}}$ concentration of very fine sandy silts is much higher than the concentration of supported ${ }^{210} \mathrm{~Pb}$ and shows a systematic decrease in ${ }^{210} \mathrm{~Pb}_{\text {ex }}$ concentration with depth indicative of the decay profile for this isotope expected in sediments that have accumulated gradually. The relatively high levels of ${ }^{210} \mathrm{~Pb}_{\mathrm{ex}}$ and its systematic decay profile in very fine sandy silts are interpreted as the product of gradual accumulation of these sediments. 

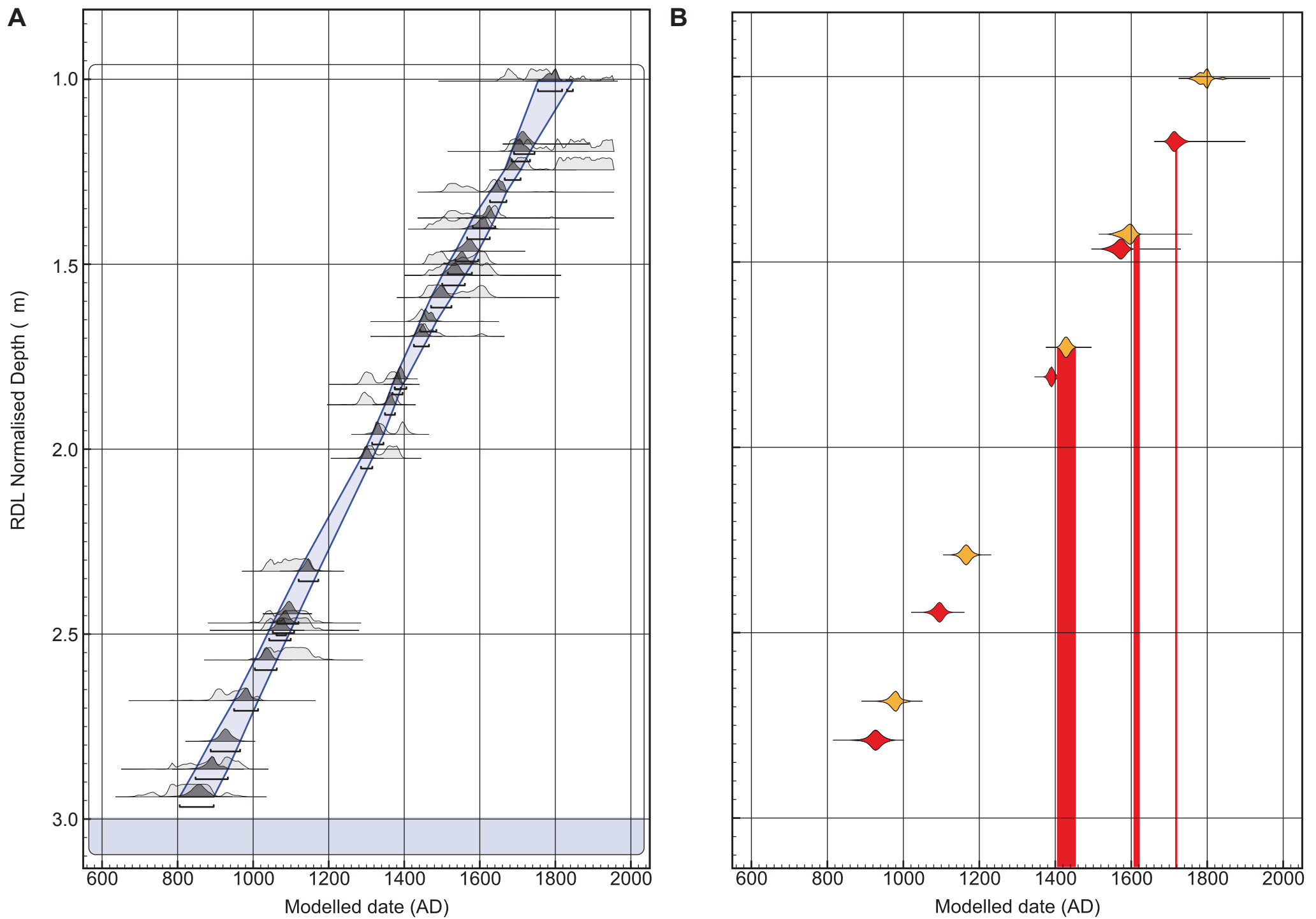

Figure DR3: $P$ sequence model chronology for core PA1. a) Modeled chronology using the $P$ sequence algorithm with the k constant equal to 2 (Bronk Ramsey, 2008) and the southern hemisphere calibration curve (McCormac et al., 2004). Calendar age likelihood (light grey) and posterior (dark grey) $95.6 \%$ probability density functions (PDF) for each radiocarbon date and the age depth relationship (blue). b) Calendar age PDFs for megaturbidite (red) deposition and the end of post-seismic sediment pulses (yellow) derived from the P_sequence age model. Red lines represent dates for the last three Alpine Fault earthquakes with line thickness representing the uncertainty (dates from Sutherland et al., 2007). RDL normalised depth is the depth of the PA1 core when deposits that were deposited rapidly, such as megaturbidites and hyperpycnal turbidites greater than $5 \mathrm{~mm}$ in thickness, were removed. 
Table DR1: Data for conventional radiocarbon ages used to establish chronology for core PA1 from Lake Paringa.

\begin{tabular}{|c|c|c|c|c|c|c|c|c|c|c|}
\hline Lab Code & $\begin{array}{c}\text { Sub- } \\
\text { bottom } \\
\text { depth }(\mathrm{m})\end{array}$ & $\begin{array}{c}\text { RDL } \\
\text { normalized } \\
\text { depth } \\
(\mathrm{m}) \\
\end{array}$ & Macrofossil & $\begin{array}{l}\delta^{13} \mathrm{C} \\
(\%)\end{array}$ & $\begin{array}{l}\text { Error } \\
(1 \sigma)\end{array}$ & $\begin{array}{l}\text { Percent } \\
\text { modern } \\
\text { carbon }\end{array}$ & $\begin{array}{l}\text { Error } \\
(1 \sigma)\end{array}$ & $\begin{array}{l}{ }^{14} \mathrm{C} \text { Age } \\
\text { (yrs BP) }\end{array}$ & $\begin{array}{l}\text { Error } \\
(1 \sigma)\end{array}$ & $\begin{array}{c}95 \% \text { calibrated } \\
\text { calendar age } \\
\text { ranges } \\
\text { (AD) }\end{array}$ \\
\hline OZM942 & 1.074 & 1.025 & Leaf - N. menziesii & -26.6 & 0.1 & 97.46 & 0.35 & 205 & 30 & $1754-1846$ \\
\hline OZM943 & 1.811 & 1.215 & Leaf - N. menziesii & -28.2 & 0.1 & 97.89 & 0.33 & 170 & 30 & $1684-1733$ \\
\hline OZN485 & 1.859 & 1.265 & Leaf - N. menziesii & -29.6 & 0.1 & 98.19 & 0.36 & 145 & 30 & $1666-1708$ \\
\hline OZN487 & 1.922 & 1.325 & Leaf - N. menziesii & -28 & 0.2 & 96.18 & 0.33 & 315 & 30 & $1627-1670$ \\
\hline OZN488 & 1.988 & 1.395 & $\begin{array}{l}\text { Leaf }-W \text {. } \\
\text { racemosa }\end{array}$ & -26.3 & 0.1 & 96.19 & 0.32 & 310 & 30 & $1581-1641$ \\
\hline OZN504 & 2.023 & 1.425 & $\begin{array}{l}\text { Leaf }-W \text {. } \\
\text { racemosa }\end{array}$ & -31 & 0.1 & 95.47 & 0.36 & 375 & 30 & $1566-1626$ \\
\hline OZM934 & 2.256 & 1.52 & Leaf - N. menziesii & -25.9 & 0.1 & 95.17 & 0.31 & 395 & 30 & $1515-1579$ \\
\hline OZN489 & 2.283 & 1.55 & Leaf - N. menziesii & -31.6 & 0.1 & 95.53 & 0.37 & 370 & 35 & $1500-1560$ \\
\hline OZN490 & 2.348 & 1.61 & Leaf - N. menziesii & -28.5 & 0.2 & 95.02 & 0.44 & 410 & 40 & $1471-1525$ \\
\hline OZN567 & 2.403 & 1.67 & Leaf - Unknown & -30 & 0.3 & 94.06 & 0.35 & 490 & 30 & $1442-1485$ \\
\hline OZM938 & 2.453 & 1.715 & Leaf - N. menziesii & -31.4 & 0.1 & 94.39 & 0.36 & 465 & 35 & $1425-1465$ \\
\hline OZM932 & 3.01 & 1.845 & Leaf - N. menziesii & -29.1 & 0.1 & 91.57 & 0.3 & 710 & 30 & $1369-1395$ \\
\hline OZN506 & 3.135 & 1.9 & $\begin{array}{l}\text { Leaf }-W \text {. } \\
\text { racemosa }\end{array}$ & -28.7 & 0.1 & 91.35 & 0.33 & 725 & 30 & $1349-1375$ \\
\hline OZN492 & 3.219 & 1.98 & $\begin{array}{l}\text { Leaf - } W \text {. } \\
\text { racemosa }\end{array}$ & -30.7 & 0.1 & 92.49 & 0.34 & 625 & 30 & $1315-1345$ \\
\hline OZN493 & 3.285 & 2.045 & $\begin{array}{l}\text { Leaf }-W \text {. } \\
\text { racemosa }\end{array}$ & -29.4 & 0.1 & 91.69 & 0.31 & 695 & 30 & $1285-1315$ \\
\hline OZM940 & 3.70 & 2.35 & Leaf - N. menziesii & -29.1 & 0.1 & 88.4 & 0.3 & 990 & 30 & $1120-1172$ \\
\hline OZN495 & 4.338 & 2.49 & $\begin{array}{c}\text { Leaf - D. } \\
\text { cupressinum }\end{array}$ & -28 & 0.2 & 88.37 & 0.37 & 1000 & 35 & $1052-1108$ \\
\hline OZM939 & 4.360 & 2.51 & Leaf - N. menziesii & -28.6 & 0.1 & 88.42 & 0.27 & 990 & 25 & $1042-1099$ \\
\hline OZN497 & 4.438 & 2.59 & $\begin{array}{c}\text { Leaf }-D \text {. } \\
\text { cupressinum }\end{array}$ & -29.7 & 0.1 & 88.27 & 0.39 & 1000 & 40 & $1004-1062$ \\
\hline OZM935 & 4.552 & 2.70 & $\begin{array}{c}\text { Leaf - } D \text {. } \\
\text { cupressinum }\end{array}$ & -27.4 & 0.3 & 86.7 & 0.35 & 1145 & 35 & $949-1013$ \\
\hline OZM499 & 5.190 & 2.885 & $\begin{array}{l}\text { Leaf }-D \text {. } \\
\text { cupressinum }\end{array}$ & -27.3 & 0.1 & 86.06 & 0.32 & 1205 & 30 & $847-933$ \\
\hline OZN501 & 5.275 & 2.96 & Twig & -25.2 & 0.2 & 85.57 & 0.33 & 1250 & 35 & $805-895$ \\
\hline
\end{tabular}


Table DR2: Data table of the metrics used to calculate the proportion of total sediment flux driven by earthquakes. MT = megaturbidite, PS = post-seismic sedimentation, AS = aseismic sedimentation and AF = Alpine Fault. All errors are reported as $95.6 \%$ highest probability density functions unless stated otherwise and have been derived by propagating the error associated with parameters estimated using the chronological model.

\begin{tabular}{|c|c|c|c|c|c|c|c|c|c|c|c|}
\hline Seismic cycle & $\begin{array}{l}\text { Date of Alpine } \\
\text { Fault rupture } \\
\text { (yrs AD) }\end{array}$ & $\begin{array}{c}95 \% \text { age } \\
\text { range for MT } \\
\text { deposition } \\
\text { (yrs AD) }\end{array}$ & $\begin{array}{l}95 \% \text { age } \\
\text { range for end } \\
\text { of PS erosion } \\
\text { (yrs AD) }\end{array}$ & $\begin{array}{l}\text { Total dry mass } \\
\text { of clastic } \\
\text { sediment } \\
\text { (g) }\end{array}$ & $\begin{array}{c}\text { Dry mass of } \\
\text { clastic } \\
\text { sediment in } \\
\text { PS phases } \\
(\mathrm{g}) \\
\end{array}$ & $\begin{array}{c}\text { \% of total } \\
\text { sedimentation } \\
\text { in each PS } \\
\text { phases }\end{array}$ & $\begin{array}{l}\text { Duration of PS } \\
\text { erosion } \\
\text { (yrs) }\end{array}$ & $\begin{array}{l}\text { PS rate } \\
\left(\mathrm{g} \mathrm{yr}^{-1}\right) \S\end{array}$ & $\begin{array}{l}\text { AS rate } \\
\left(g_{y r}^{-1}\right) \S\end{array}$ & $\begin{array}{c}\text { Mass of PS } \\
\text { sedimentation } \\
\text { related to AF } \\
\text { earthquakes } \\
\text { (g) } \\
\end{array}$ & $\begin{array}{c}\% \text { of total } \\
\text { sediment flux } \\
\text { driven by AF } \\
\text { earthquakes }\end{array}$ \\
\hline 1 & 1717 & $1745-1690$ & $1848-1753$ & 2212 & 760 & 12.1 & $78 \pm 27$ & $9.7 \pm 3.5$ & $6.8 \pm 1.4$ & & \\
\hline 2 & ca. 1620 & $1596-1535$ & $1617-1556$ & 473 & 71 & 1.1 & $22 \pm 16$ & $3.2 \pm 2.4$ & $3.2 \pm 0.9$ & & \\
\hline 3 & ca. 1430 & $1405-1374$ & $1448-1410$ & 1046 & 600 & 9.5 & $39 \pm 16$ & $15.4 \pm 6.3$ & $3.2 \pm 0.8$ & & \\
\hline 4 & N/A & $1120-1064$ & $1191-1140$ & 1606 & 766 & 12.2 & $72 \pm 24$ & $10.6 \pm 3.5$ & $3.8 \pm 0.5$ & & \\
\hline 5 & N/A & 965- 887 & $1011-946$ & 963 & 560 & 8.9 & $51 \pm 22$ & $11.0 \pm 4.7$ & $3.5 \pm 0.4$ & & \\
\hline Average & & & & & & $10.7 \pm 3.4(2 \sigma) \dagger$ & $52 \pm 22 \dagger$ & $11.7 \pm 4.7 \dagger$ & $4.1 \pm 0.9$ & & \\
\hline Total & & & & 6301 & $2686+$ & 41.8 & $240 \pm 45 \dagger$ & & & $1711 \pm 289$ & $27 \pm 5$ \\
\hline
\end{tabular}

* Alpine Fault earthquake dates from Sutherland et al. (2007).

$\dagger$ The ca.1620 earthquake excluded from consideration because it did not rupture the Alpine Fault adjacent to Lake Paringa.

$\S$ Divide these values by the sediment core cross-section area $\left(19.5 \mathrm{~cm}^{2}\right)$ for sedimentation rates in the units $\mathrm{g} \mathrm{cm}^{2} \mathrm{yr}^{-1}$, which are reported in the main text. 